\title{
Identification of Key Forces Influencing Sustainable Development in Taiwan
}

\author{
S'harin Mokhtar ${ }^{1} \&$ Yi-Shin Deng ${ }^{1}$ \\ ${ }^{1}$ Institute of Creative Industries Design, National Cheng Kung University, Tainan \\ Correspondence: S'harin Mokhtar, Institute of Creative Industries Design, National Cheng Kung University, No.1, \\ University Road, Tainan City 70101, Taiwan. Tel: 886-9-3976-6444. E-mail: sharin2901@gmail.com
}

Received: February 2, 2015 Accepted: February 26, 2015 Online Published: March 30, 2015

doi:10.5539/jsd.v8n2p174 URL: http://dx.doi.org/10.5539/jsd.v8n2p174

\begin{abstract}
This paper presents a comprehensive macro-environment analysis through a political, economic, social, technological (PEST) analysis approach. This study provides an analysis of eleven reports published by the National Council of Sustainable Development in Taiwan between 2003 and 2013 in order to lead to an understanding of sustainable development in Taiwan. The results identified 9 key forces in the political environment, 8 key forces in the economic environment, 10 key forces in the social environment and 5 key forces in the technological environment that can have an influence on sustainable development in Taiwan.
\end{abstract}

Keywords: macro-environment, PEST analysis, sustainable development

\section{Introduction}

From the past 10 years, Taiwan's environment has suffered serious destruction and pollution causing the disappearance of biodiversity, dwindling of forest, worsening water quality and affects the island's sustainability. The globe's changing climate and frequent occurrences of extreme natural disasters such as earthquake and typhoons due to human continued in their path of over development and over utilization of biological resources (NCSD, 2004, 2011, 2012, 2014). Besides that, the demand-oriented approach of economic development that is wrong conception in placing importance on the size of projects over the functions, which caused the irreparable damages to the environment.

Realizing the importance of sustainable development in Taiwan, many industries have tried to amplify sustainability element in their organizations. However, in order to achieve sustainability objectives, it is crucial that the stakeholders of the industry understand the macro-environment. According to Olsen (2004), the success of an organization will depend on how well it is able to identify the forces that will drive change, invest in industry leading competitive methods that will take advantage of the opportunities presented by these forces and consistently allocate resources to these methods. It requires a thorough understanding of each of the variables that have significant influence in shaping that force. Macro-environment provides the business opportunities to the industry; yet, the macro-environment is also a source of threats - forces that may impede the successful implementation of a strategy. An organization usually achieves its desired level of success if successful in this endeavor (Olsen \& Roper, 1998). Identifying the industry in which an organization competes in order to achieve sustainability is a logical starting point for analyzing its external context.

To analyze the macro-environment, this study employs a political, economic, social, technological (PEST) approach to develop an understanding of the big picture of the macro-environment related to sustainable development. For this to achieved, the annual reports published by the National Council of Sustainable Development in Taiwan are analyzed to provide a non-exhaustive list of potential influences of the environment in a business. This will help the organizations gain better understanding of the opportunities and threats they face and consequently aid them in building better vision of the future business landscape and how the industries might achieve sustainability.

\section{An Overview of Sustainable Development in Taiwan}

The United Nations has convened the Earth Summit in 1992 to endorsed Agenda 21 to serve as the action plan for promoting the sustainable development to the world (Keating, 1992). Due to international pressure and democratization that has given rise to a stronger social concern for the environment, Taiwan established the 
Committee on Global Change Policy which later became the National Council on Sustainable Development (NCSD) on August 23, 1997 (NCSD, 2004). The function of the NCSD is to integrate sustainable development-related work in order to raise national competitiveness in the movement for global sustainable development movement.

The year 2003 was designate as the first year of sustainable development in Taiwan. The public was urged to work together pursuing Taiwan's sustainable development because of its limited natural resources, dense population and frequent natural disasters (NCSD, 2004). In order to cultivate cooperation between the government and industries in the area of sustainable development, the government has developed a plan for structural adjustments to industries and the promotion of high added value, low energy consumption industries and technologies in order to create a win-win strategy that benefits both the economy and the environment (NCSD, 2005).

In the interest of encourage all people in Taiwan to participate in promoting sustainable development and put the concepts into practices with emphasis on localization and relevance to daily living, NCSD has organize Taiwan Sustainable Development Award annually (NCSD, 2005, 2006, 2007, 2008, 2009, 2010, 2011, 2012, 2013, 2014). The award includes five categories which are Best community in Sustainable Development, Sustainable Development Education, Best Enterprises in Sustainable Development, Best Association in Sustainable Development and Best Action Plan Implementation (NCSD, 2004).

On this long path, the NCSD has actively promoted sustainable development in Taiwan by facilitating cross-ministerial mobilization, bringing theory into practices in each ministry's business affairs and by adjusting policies in accordance with sustainability concepts. However, in order to continue the advancement in sustainability, an in-depth study on the macro-environment is needed to provide a big picture of sustainable development in Taiwan to organization.

\section{Method}

According to Porter (1985), the essence of formulating a competitive strategy is relating an organization to its environment in relation to the industry or industries with which it competes. Therefore, in this paper a PEST analysis has been employed to determine the political, economic, social and technological factors in the macro-environment by which to identify the political, economic, social and technological factors that influence an industry in terms of sustainability.

PEST analysis is use by organizations for the purpose of identifying the external market factors that could influence an organization or entire industry. PEST analysis is formed according to four macro-environmental factors: political factors, economic factors, social factors, and technological factors. The analysis examines the impact of each of the factors on a business for which the results can be used to take advantages of opportunities and to make contingency plans for threats when preparing business and strategic plans (Byars, 1991). PEST analysis also ensures that organization's performance is aligned positively with the powerful forces of change that are affecting business environment (Porter, 1985).

In this study, a PEST analysis was employed to analyze the Annual Report on National Sustainable Development published by the National Council for Sustainable Development, Taiwan, R.O.C. The analysis included a relatively official report published from 2003 to 2013 consisting of eleven separate reports. For the purpose of this study, these reports were select based on their relevance to the sustainable development in Taiwan. These reports were examined in order to identify key forces influencing the sustainability of the macro-environment in Taiwan.

This study approached the selected annual reports from two perspectives. First, each annual report was evaluated for the presence or absence of each of four types of environmental forces: political, economic, social and technological. The annual reports were evaluated independently and discrepancies were identified and resolved. This perspective is base on the concept of matching words from the aspects of political, economic, social and technological. The following keywords were use to identify reports for inclusion in the study: sustainable development, political, economic, social and technological.

Next, another perspective is follows a correlation or pattern-recognition strategy where the text from the point of view that both what is said and how it is said in the context of other thoughts is what matters. Terms with similar meaning to the keywords such as political, economic, social and technological is group into common category. In this perspective, political refers to government policies like fiscal, monetary, industrial, labor and export and import policies, which are influence to the business organization political legal function and degree of the effectiveness in achieving sustainability. Economic environment refers to the nature and direction of the 
economy, the general economic situation in the region, conditions in resource markets, development process of the country, level of the economic income of the country, distribution of income and assets of the country and public finance on the country within an organization. Social environment consists of factors which are related to human relationships and the impact of social attitudes and cultural values such as the role of sustainable development in the society, environment pollution, corruption, consumption of natural resources, life style patterns, role of the women, position, nature of responsibilities in society, and educational level, awareness towards sustainability. Technological environment consists of the opportunities that arising out of technological developments, technology changes and research and development role to a country. At this stage, categories were generated to identify key themes in the text. The final process is returns to the original body of text and examines these key words or categories in context.

\section{Results and Discussions}

A PEST analysis classifies issues as political (P), economic (E), social (S), and technological (T). In the context of this paper, the PEST criteria is focused on issues that organizations should address in order to ensure sustainable diffusion and adoption of solutions that can help a country achieve sustainability.

The main focus of this paper is to identify the key forces that influence the macro-environment related to sustainable development in Taiwan. PEST analysis was employed, and the key forces were categorized based on four factors, political, economical, social and technological as shown in Table 1.

Table 1. Key forces influencing sustainable development in Taiwan

\begin{tabular}{|c|c|c|}
\hline \multirow[b]{2}{*}{ Environments } & \multicolumn{2}{|c|}{ Key Forces } \\
\hline & Opportunities & Threats \\
\hline Political & $\begin{array}{l}\text { - } \begin{array}{l}\text { Development of policies, management } \\
\text { mechanisms, strategies and action guidelines }\end{array} \\
\text { - } \quad \begin{array}{l}\text { Regular revisions on strategies, action plans } \\
\text { and systems }\end{array} \\
\text { - } \quad \text { Allocation of fund and budget for sustainable } \\
\text { development } \\
\text { - } \quad \text { Enhancement of public participation } \\
\text { Staying abreast of the latest international } \\
\text { trends on sustainable development }\end{array}$ & $\begin{array}{l}\text { - } \quad \text { Lack of coordination and integration } \\
\text { across agencies } \\
\text { - Incapability of current centralized } \\
\text { and localized government structure } \\
\text { - Barred from obtaining United } \\
\text { Nations membership } \\
\text { - Restrained from using the name } \\
\text { "Taiwan" }\end{array}$ \\
\hline Economic & $\begin{array}{l}\text { - } \quad \text { Promotion of green businesses } \\
\text { - } \quad \text { Promotion of green consumption } \\
\text { - } \quad \text { Piversification in the development of } \\
\text { traditional industries } \\
\text { - Promotion of energy conservation and carbon } \\
\text { reduction }\end{array}$ & $\begin{array}{l}\text { - } \quad \text { Decline of primary industries } \\
\text { - } \quad \text { Imbalances in power demand and } \\
\text { supply } \\
\text { - High cost of renewable energy }\end{array}$ \\
\hline Social & $\begin{array}{l}\text { Integration of sustainability knowledge in } \\
\text { education } \\
\text { - } \\
\text { Raise public awareness of sustainable } \\
\text { development } \\
\text { Enhancement of better quality of life for } \\
\text { communities } \\
\text { - Improvement of public transportation } \\
\text { - Implementation of health management and } \\
\text { monitoring } \\
\text { Enhancement of welfare and equality for } \\
\text { disadvantaged people, children, women and } \\
\text { the elderly } \\
\text { - Cultivation of culture and heritage }\end{array}$ & $\begin{array}{l}\text { - Exploitation of native vegetation and } \\
\text { over-cultivation for large-scale } \\
\text { planting } \\
\text { - } \quad \text { Large financial gap between the rich } \\
\text { and the poor } \\
\text { - Insufficient laws in land } \\
\text { development requirements }\end{array}$ \\
\hline Technological & $\begin{array}{l}\text { - Promotion of research and development } \\
\text { - Created assistance systems for sustainable } \\
\text { development } \\
\text { - Coordination of national and domestic } \\
\text { industry } \\
\text { - Knowledge sharing and experience exchange }\end{array}$ & - Limited knowledge and data \\
\hline
\end{tabular}




\subsection{Political}

Based on the analysis in this study, opportunities and threats serving as the key forces influencing the political environment in Taiwan are shown as below:

\section{Development of policies, management mechanisms, strategies and action guidelines}

After the Earth Summit in Rio de Janiero in 1992, Taiwan issued its own Agenda 21, National Report on Biodiversity, National Environmental Protection Plan, and a plan for developing Taiwan into a "Green Silicon Island" (Council for Economic Planning and Development, 2004). Of these, the NCSD has developed many management mechanisms, strategies and action guidelines for national sustainable development. The Taiwan Declaration on Sustainable Development was drafted to carry out sustainable development based on the principles of equality between generations, social justice, equal emphasis on the environment and development, knowledge-based economy, human rights protection, education promotion, respect for aboriginal traditions, international participation (Hsu, 2013; NCSD, 2005). NCSD also ratified the Taiwan Agenda with the basic strategies and action guidelines for Taiwan in response to the challenges of 21 st century, including an overview of Taiwan's unique environment, Taiwan's vision for sustainable development as well as principles and course for sustainable development and the guidelines for the National Sustainable Development Strategy (NCSD, 2006).

In order to respond to the United Nation's request for each country to establish an indicator system, the NCSD has adopted Taiwan Sustainable Development Indicators (SDI) to assess the progress of sustainable development (NCSD, 2004; Tsai, 2010). Yet, in order to stay on track with international trends, the NCSD resolved to amend Taiwan's Sustainable Development Indicator System in 2008, which was approved in 2009 (NCSD, 2011). The new SDI system includes 12 themes, 41 sub-themes and 86 indicators.

Moving toward a zero waste society, the government drafted the Urban Waste Management Plan to treat general waste effectively. Many plans have been drafted and implemented since then, such as the Garbage Management Plan, the Resource Recycling Plan, the "Garbage Treatment Plan Evaluation and Vision", the announcement of "Year of Action toward Complete Sorting of Garbage for Zero Waste" and the Mandatory Garbage Sorting Policy (NCSD, 2008). In addition, NCSD has conducted the first onsite survey of Dongsha Island National Park in the effort to establish this national park as a park that follow the principles of zero-waste and zero- $\mathrm{CO}_{2}$ emissions and to minimize the amount of concrete used in the park (NCSD, 2006).

\section{Regular revisions on strategies, action plans and systems}

Regular revision is needed on the strategies, action plans and systems to ensure that more efficiency of sustainable development work (OECD, 2006). In addition to the revision of the SDI system, the Sustainable Development Action Plan is regularly revised, with updated plans every half a year (NCSD, 2010). The revised Sustainable Development Actions Plans has been made to better correspond to the second version of the SDI system. The modification of action plans for sustainable development was intended to enable the study of the relationship between the outcome document and Taiwan's ongoing documents on sustainable development, and to review the action plans of various units, strategies and actual implementation in order to incorporate the outcome document "The Future We Want" into the NCSD promotional tasks (NCSD, 2014).

\section{Lack of coordination and integration across agencies}

Even though the indicator as been the same since 2001, it experienced a large decline in terms of assistance given toward advancing sustainable development works in 2006 (NCSD, 2008). Ling-Ling Lee, a Professor at the Institute of Ecology and Evolutionary Biology at National Taiwan University pointed out that there is a lacking of coordination and integration across agencies. This is because many of the NCSD working group's action plans have not been updated and follow up evaluation mechanisms are relegated so that each government agency has to perform on its own (NCSD, 2010, 2013). In a word, networks require active leadership or management, to compliment and reinforce any willingness shown by individual actors to coordinate amongst themselves (Adelle, Hertin, \& Jordan, 2006).

\section{Incapability of current centralized and localized government structure}

The current centralized and localized government structure is incapable of achieving ideals that include vertical integration and comprehensive development in sustainable development (NCSD, 2014). Due to this, Alice Yu, Chairperson of the Yu Chi-Chung Cultural and Educational Foundation suggested that the vertical integration occurring between the Councils for sustainable development in the central and local government should strengthen. Chun-Hsin Lin, Chairman of the Archlife Research Foundation also mentioned that, although there are many goals, policies and corresponding action plans, the Taiwanese do not know whether these action plans are complementary to the other plans that are already in effect (NCSD, 2013). The Chairman suggested that a set 
of self-assessment tools to self-evaluate is needed. Besides this, the turn-over rate is too high because civil members of the Council only serve a one year term, preventing some members from showing their full potential (NCSD, 2010). Progress on the implementation process and efficiency are difficult to track by simply relying on the participation of the small number of NCSD members and their meetings (NCSD, 2014). Phillips (1996) in his book mentioned that "an excessive turnover rate clearly has a tremendous negative impact on an organization's cost".

\section{Enhancement of public participation}

The indicators showed a decrease in 2007 and 2008 for government initiated provision of resources, thus indicating that there is still room for improvement in regard to both government responses and citizen action (NCSD, 2009, 2010). In order to encourage all people in Taiwan to participate in promoting sustainable development, the NCSD has organized the Taiwan Sustainable Award which includes five categories that focus on the participation of communities, education sectors, private sectors, non-government organizations and related government departments (NCSD, 2004, 2007). The government had work together with the private sector to implement the concepts and promote Taiwan sustainable development (Department of Information Services, 2014). However, schools that participate in the awards are dropping in number because it is an extra burden to the schools to allocate resources to cater to the special learning environment of the new resident students, to facilitate after-class counseling and to strengthen their social adaptability and communication skills (NCSD, 2014).

Heikkila and Isett (2007) argued that it is difficult to promote citizen participation in policy-making, which requires different kinds of citizen opinions and participations. To strengthen the participation of citizen in sustainable development policy making, the NCSD has organized forums including scholars, industry representatives, related council members, and government representatives, including high-level officers to exchange views on sustainable development. In addition, the Guidelines for Establishing the National Council for Sustainable Development were revised to enhance the participation of experts from different fields (NCSD, 2006). The processes of formulating policy often provide numerous opportunities for different stakeholder representatives to express their views and develop a consensus (NCSD, 2010, 2011).

\section{Staying abreast of the latest international trends on sustainable development yet barred from obtaining} United Nations membership and restrained from using the name "Taiwan"

The government has actively participated in international sustainable development activities to stay abreast of the latest international trends in sustainable development and to ensure that Taiwan develops corresponding response strategies (NCSD, 2006). However, since Taiwan was barred from obtaining United Nations membership and restrained from using the name "Taiwan" when participating in related international convention activities (Friedman, 2006), the government has actively integrated the forces of industry and non-government to expand cooperation internationally.

\subsection{Economic}

Based on the analysis conducted in this study, opportunities and threats that are key forces influencing the economic environment in Taiwan are shows as below:

\section{Promotion of green businesses}

In order to move towards a green economy, the Taiwan Environmental Protection Agency has launched a trial plan called the Indicator of Sustainable Economic Welfare (ISEW) to serve as a reference for compiling the Green GDP (NCSD, 2006). Compiling the Green GDP enables the establishment of information on how the economic system affects the ecosystem by effectively evaluating and balancing the results of economic development to portray standards of living and welfare as sustainable development indicators.

The green business concept has been promoted by establishing a green business database to provide assistance to green businesses including supervision of demonstration sites, guidance to markets to establish green businesses and environmental protection committees, green business training courses and assistance to business applying for research plans to make packaging more environmental friendly (NCSD, 2006). These actions show that the government of Taiwan is aware of the necessity of seeking economic transition to respond to climate-change issues (Chao, Ma, \& Heijungs, 2013).

\section{Promotion of green consumption}

In the effort to promote green consumption, the government has established marketing channels for environmentally friendly products (NCSD, 2012; Tsay, 2009). Taiwan also signed mutual recognition agreements 
with eco-label organizations in seven countries to promote the purchase of Green Mark products (NCSD, 2005; Tsay, 2009). On top of this, the government has assisted the planning of second-hand markets, developed relevant management talent, enabled distribution channels and promoted meaningful use of vacant market lots while generating business in the process (NCSD, 2008, 2014). In addition, the government has also assisted second-hand markets with their promotional plans such as printing promotional materials, a code of conduct for selling second-hand goods, personnel training, demonstration workshops, press conferences and exhibition of achievements as well as television and other promotional media (NCSD, 2009).

\section{Promotion of green building}

As part of promoting the green building, the government has added Green Building Codes to the building design and construction section of the building technology codes (Wu \& Chang, 2013). In addition, the government also drafted the Ministry of the Interior Award for Private Sector Green Building Reform Model Operating Guidelines to promote green building design for existing buildings in the private sector (NCSD, 2008, 2014). Subsequently, the Eco-city Green Building Promotion Plan was executed; the Building Energy Efficiency Upgrade Plan was implemented, and Green Building Environment Education Demonstration Site Tours were conducted (NCSD, 2011).

\section{Diversification in the development of traditional industries due to the decline of primary industries}

Agriculture is one of the most important sectors of the Taiwanese economy. However, primary industry development is decline throughout the country, especially in Yunlin County (NCSD, 2009). Taiwan's overall economic structure has been shifting the focus away from the agricultural industry toward industrial, commercial and service industries. According to Yophy, Jeffrey, and Yu (2011), Taiwan has transformed itself from an underdeveloped, agricultural island to an economic power that is nowadays a leading producer of high-technology goods. In order to promote sustainable development in agriculture, some counties and cities in Taiwan have diversified the development of traditional agricultural by gradually evolved in the diversified development of advanced technology, culture, tourism and manufacturing industries, as well as working towards the advancement of sustainable ecological development related to natural ecology, living environments, green production and green construction (NCSD, 2005, 2009). Some non-governmental organizations also have switched to more refined agricultural development in cooperation with economic development.

\section{Imbalances in power demand and supply, and the high cost of renewable energy}

Energy is the key issue of sustainable development in Taiwan (NCSD, 2005) because $98 \%$ of Taiwan's energy resources are imported (NCSD, 2004, 2006, 2014). With the rapid industrialization and economic development in the past decades, the national energy consumption tends to be larger with economic growth, resulting in high-energy dependence (MOEA, 2003). The introduction of wind energy development was hampered due to the fact that unstable wind caused imbalance in power demand and supply and the fact that the cost of renewable energy is higher in developed countries like Taiwan (NCSD, 2004). This has made energy conservation and carbon reduction an important focus in helping the country to achieve sustainable development. The executive Secretary of the Energy Commission suggested modification of the policy on the development of renewable energy due to the world trend toward developing green energy (NCSD, 2004). He proposed that a series of measures should be launch after consolidating efforts from the private sector to ensure a stable supply of energy in Taiwan. Adoption of laws that ensure a public policy favoring the continued use of renewable energy is needed to lead Taiwan to becoming a nuclear-free island.

\section{Promotion of energy conservation and carbon reduction}

The government promulgated the Renewal Energy Development Act and held the National Energy Conference to promote a low-carbon economy (NCSD, 2010). The government also gives advice on energy conservation and carbon reduction by setting up energy conservation and carbon reduction teams for the fishery industry. Energy integrated industrial parks has been promoted by establishing the foundation of the Environmental Science and Technology Park (ESTP) Plan (NCSD, 2009); and greenhouse gas inventories were conducted to assist the manufacturers in Taiwan with promoting greenhouse gas reductions and the development of renewable energy (NCSD, 2011, 2012). The aim was to raise annual renewable energy production by 2.5 times by 2010 and by 5 times by 2020 to coordinate with the 2008 National Development Plan (MOEA, 2008; NCSD, 2004)

\subsection{Social}

Based on the analysis conducted in this study, the opportunities and threats that are the key forces influencing the social environment in Taiwan are shown as below: 


\section{Integration of sustainability knowledge in education}

In order to advance public awareness of sustainable development, the government of Taiwan completed a draft of the "Environmental Education Act" by integrating resources in order to promote sustainable development education (NCSD, 2005, 2006, 2007, 2012, 2013) and also introduced the "Sustainable Campus Movement" to promote education with a community flavor (NCSD, 2007, 2014). The government completed a sustainable education teaching module to integrate resources and the development of sustainable educational materials and teaching methods (NCSD, 2013, 2014).

In addition, the "Sustainable Campus Promotion Plan" was implemented to encourage schools at all educational levels to carry out campus reform plans (NCSD, 2004, 2005, 2008, 2010, 2012). A sustainable education promotion center were established to subsidize projects and promote biodiversity education and sustainable development education (NCSD, 2005). Schools' building lifecycles has been enhanced and transformed into bases for environmental education that accord with sustainable development (Shih, Chen, Tzeng, Hsieh, \& Liu, 2013). Schools and colleges were also subsidized to improve the campus environment (NCSD, 2009). A series of environmental education guidance workshops were held for local government officers to promote and implement environmental education, as well as press conferences to encourage people to make environmental protection a part of their daily lives (NCSD, 2007, 2011, 2013, 2014).

\section{Raise public awareness of sustainable development}

In addition, in an effort to implement sustainability across the board in the environment, industry and society as a whole, civil society has been involved throughout the process of sustainable development. Schools have integrated communities to create a comprehensive educational network (NCSD, 2005, 2008). Some non-government organizations have established partnerships with communities and the government with the purpose of asserting the public's standpoint. Workshops and courses are held to cultivate local volunteerism and contribute to environmental activities and education (NCSD, 2006, 2007, 2009). Involving communities in these activities changes their mindsets and promotes ideas related to sustainability as well as raising awareness of environmental issues (NCSD, 2010).

\section{Enhancement of better quality of life for communities}

In order to enhance quality of life for communities with a safe, healthy and clean environment, environmental quality management and monitoring has been effectively implemented. The government has established guidelines to carry out environmental monitoring of various pollutants. National Health Risk Assessment Guidelines and Division of Labor and Work Procedures for Crisis Management for Unanticipated Pollution Incidents were established to reduce the impact of environmental pollutants on public health (NCSD, 2005, 2009, 2013). Health Risk Monitoring for specific pollutants was introduced to carry out environmental monitoring of various pollutants and to serve as a reference for future revisions (NCSD, 2005). According to Hung et al. (2012), the Environmental Protection Administration (EPA) in Taiwan has established a network of 66 air pollution monitoring stations in 66 municipalities in 1994. On top of that, the infectious disease surveillance system was strengthened to stop the spread of epidemics and eliminate infectious disease transmission at the border (NCSD, 2008). The "Stockholm Convention on Persistent Organic Pollutants National Implementation Plan" was drafted to monitor the water quality and environment of rivers (NCSD, 2009).

\section{Exploitation of native vegetation and over-cultivation for large-scale planting}

A member of the NCSD, Chih-Wei Yang points out that the Society for Taiwan Indigenous People's Policies (YIPPA) is concerned not only about the policies related to the nation's indigenous people, but also about sustainable development issues (NCSD, 2004). He stressed that sustainable development concepts should include sustaining life, culture, ethnic groups and resources because sustainability is not limited to environmental conservation, but also encompasses a profound integration of nature and the land as well.

According to the laws, forest is primarily the property of the state. Any private use of the resources in the national forest without the approval of the forest authority is illegal. This has cause the indigenous people who live in the mountain can only rely on the resources within very confined pieces of land that are called 'Indigenous Reserve Land', usually surrounded by national forest which has been exploited for development (Hsiao, 2008). Chih-Wei Yang also suggested that mainstream society stop its current development measures and exploitive habits. Native vegetation has been exploited and deliberately over-cultivated for large-scale plantations since the mainstream society invaded the traditional territories that used to sustain the indigenous people of Taiwan (NCSD, 2011). 


\section{Improvement of public transportation}

Public transportation is an important component of daily life in a community. In the effort to improve quality of life, the government has raise public transport efficiency and passenger service standards by implementing an improvement plan to address problems with public transport (NCSD, 2010, 2011, 2012, 2013, 2014). An online transport information and new integrated road network traffic system was created to provide up to date information to citizens. According to Wei and Chung (2003), Taiwan is involved in intelligent transportation systems planning, and is now selecting its prior focus areas for investment and development. Vicky Liu, the Director of the Cycling Lifestyle Foundation suggested that the government should prioritize the uncontrolled growth of automobiles because the seating capacity is low, yet they consume large amounts of fossil fuels. The government should learn from developed countries to construct a people-centered sustainable transportation network (NCSD, 2012).

\section{Implementation of health management and monitoring}

In order to appraise and minimize national health risks, the government has established long term health information as a reference for following and formulating health policies (NCSD, 2011). Comprehensive medical services and systems were implemented to build a healthy and vibrant society. For example, a vaccination policy was implemented to provide routine vaccinations to children (NCSD, 2008, 2013; Su et al., 2015) and cancer screening services and a health risk assessment database were established (NCSD, 2009). A new system for regulating organic farm products in order to promote organic agriculture was introduced to encourage a healthy lifestyle in the population (NCSD, 2010).

\section{Enhancement of welfare and equality for disadvantaged people, children, women and the elderly}

In terms of welfare, the government has focused on welfare and equality for disadvantaged people, children, women and the elderly (Ministry Of Foreign Affairs, 2010). An "Infant Education and Care Act" was formulated to integrate all education and welfare matters pertaining to the care of children (NCSD, 2012). Protection for the weak and an actualizing welfare measure was implemented in order to provide subsidies to parents looking after their toddlers. In addition, a pilot plan for enhancing the quality of alerts related to child protection was promoted, and appropriate manuals were developed for domestic alert personnel (NCSD, 2013, 2014). As for the elderly, social protection of population ageing has been improved as more private organizations, subsidized by the government, provide social services to the elderly (Chen, 2008). A Ten Year Hospital Plan was established to care for disabled elderly individuals (NCSD, 2013), and a health promotion competition and workshop was organized to create a friendly city for the elderly and to enhance their social participation (NCSD, 2014).

\section{Large financial gap between the rich and the poor due to the insufficient laws related to land development requirements}

According to Yi-Hou Lin, the Director of Research and Development for the Urban Regeneration Foundation, the gap in wealth between the rich and the poor can be bridged by improving land use (NCSD, 2014). The Director suggested that enhancing the use of developed land to bridge this gap, thereby lowering the misery index arising from the high cost of land and housing. This supported by Hongey Chen, a professor in the Department of Geosciences at National Taiwan University, who pointed out that natural calamities have caused tremendous destruction to life and property in Taiwan and that the current laws are not sufficient in terms of land development requirements. (NCSD, 2014).

\section{Cultivation of culture and heritage}

Culture and heritage are important elements for both communities and countries because it reflects and builds local identities, aids communities' sustainability and provides a sense of place (Davis, Huang, \& Liu, 2010). In order to sustain cultural assets, a few non-governmental organizations have organized planning and execution to preserve the cultural assets of communities. The Oxplow Community Exchange Association established by local residents has organized an "Oxplow Team" to guide visitors on tours of the abundant historical cultural relics left behind in Fengtian by Japanese (NCSD, 2008). The Longdu Elementary School in the Meinong District of Kaohsiung City has integrated local industry and Hakka culture towards cultivating Hakka farming (NCSD, 2013).

\subsection{Technological}

Based on the analysis done in this study, opportunities and threats that are key forces influencing the technological environment in Taiwan are shows as below: 


\section{Promotion of research and development}

Advancements in technologies can be achieves by promoting research and development. In 2001, Taiwan had become an official affiliate member of the Global Biodiversity Information Facility (GBIF) (NCSD, 2004). By that time, Taiwan had established the Taiwan Biodiversity National Information Network (TaiBNET) to compiles databases for biological species and biodiversity specialists in Taiwan (Shao et al., 2007). In addition, an integrated platform and exchange mechanism had been established by digitizing all the various types of information into one database on the Internet to provide essential information for academic exchange and practical application, bringing the results of groundwork academic research into full play (NCSD, 2004, 2009, 2011, 2013).

In addition to these innovations, the government also carries out distributed renewable energy generation and parallel connection technology to strengthen the research and development of energy technology by drafting a statutes to develop the renewable energy (NCSD, 2007, 2013). A research and development plan was drawn up to develop biomass raw materials that use microbial stabilizer technology for biodiesel fuel to promote the development. On the other hand, maritime historic research and preservation of Dongsha Marine National Park was carried out to improve techniques related to maritime historic research and underwater archaeology (NCSD, 2009).

\section{Limited knowledge and data}

The government had promoted scientific research and the evaluation of the climate by conducting wide-ranging research projects to look into Taiwan's susceptibility to water and wind related disasters, weaknesses in local ecologies, water supply systems, public health systems and the forestry, agricultural and fisheries industries in the face of climate change (NCSD, 2009, 2010, 2012, 2013, 2014). However, Taiwan has limited knowledge about climate impacts on biota and ecosystems and lacks of historic baseline data related to climate change (NCSD, 2014).

\section{Created assistance systems for sustainable development}

In order to promote green technology and industry, the government has created the nation's first Biodiesel Demonstration System to promote renewable energy (NCSD, 2005). A biodiversity monitoring system was planned as well to monitor Taiwan's land, wetland and marine environments (NCSD, 2005). On top of this, GIS databases at four national forestry lands in Taiwan have been established. These databases employ satellite imagery to survey vegetative cover over the island. Because of this, image analysis and a survey database on the entire island's vegetative cover has been completed (NCSD, 2006). Moreover, in order to enhancing weather reporting and seismic activity forecasted, government has implemented four years of the Sea Weather E-service System integration and application plan (NCSD, 2012). A new generation of seismic observation networks has been implements for the monitoring and reporting of severe weather.

\section{Coordination of national and domestic industry}

Sustainability in technology can also be achieved by strengthening the coordination of national and domestic industrial technology (NCSD, 2009). Noticing this, the government has installed a comprehensive system to coordinate with international conventions that serves as a mechanism for policy formulation and cross-ministerial coordination (NCSD, 2005).

\section{Knowledge sharing and experience exchange}

In order to lead other localities in establishing a framework for sustainable development in technology, the Taiwanese government has organized an international forum to discuss regional, national and local environmental modeling tools as well as to encourage the exchange of related topics and experiences (NCSD, 2006, 2008)

\section{Conclusion}

In can be noted from the findings of this analysis that key stakeholders groups involvement from central government, local governments, private sectors, non-governmental organizations and civil society is needed in order to achieve sustainability in a country. However, each stakeholder is focusing in difference aspects. For example, government focuses on legal and political which related to sustainable development. At the same time, they also involved in formulation and implementation of policy in the legislature. Then, local government will implement the policies with the guidelines and actions plans created by central government at county and local level. Private sectors and non-governmental organizations will contributes in sustainable development by implement the principles of sustainability from the aspect of economic and technology, and also their 
responsibility on society. Community will support the government appeal by practicing sustainability in their daily life.

To pursue a balance between the environment, the economy and society; and to put sustainability concepts into action, related government departments need to put their policies into practice. The central government has to draw up legal guidelines, which function as a vehicle to keep the pathway toward sustainable development in Taiwan concurrent with global achievement in this area. This shows that a top-down approach is needed in addition to a bottom-up approach in order to promote sustainable development in Taiwan. The government has to play a role to focus the popularization of the importance of sustainable development within the public, who in turn monitors and promotes government policy changes. Such a top-down approach entails the clear formulation of national sustainable development policies by the government through budget allocation and discussion with scholars and experts detailing implementable sustainable policies.

Movement towards a green economy has the potential to lead to sustainable development. As shown from the findings in this study, appropriate policies are needed to build up and enhance natural capital such as forest, water and soil. Green investments will enhance new sectors and technologies that will be the main sources of economic development and growth in the future, such as renewable energy technologies, resources and green buildings, green consumption, and waste management and recycling facilities. Complementary investments are required in human capital, including greening-related knowledge, management and technical skills, in order to ensure a smooth transition to a more sustainable development pathway.

Communities can be led into a positive cycle of sustainable development by pursuing a healthy and balanced development between humans, communities and the earth. This study shows that sustainability problems can be solves by strengthening community environmental consciousness, developing community vision and integrating sustainability concepts into daily life. Private sectors should actively give back to society by implementing gender equality and taking care of the welfare of the society as a whole. Various stakeholders, including governments, investors and communities can pressure organizations to become more responsible for the welfare of society, and corporate social responsibility (CSR) has become an important issue in many industries (Kim \& Kim, 2014).

A common reaction to the problems attributed to technologies is to argue that the problem is not so much in the technology but in how it is uses or abuses. The advancement of sustainability in technology can be achieve by promoting the related research and development, the enhancement of assistance systems, the coordination of national domestic industries and knowledge sharing and experience exchange with developed countries. Sustainable development relies on technological change to achieve its aims and needs governments to take the tough steps that are required to force radical technological innovation rather than the technological fixes that have been evident to date.

In conclusion, there are many opportunities and threats associated with sustainable development, all of which may be consider most crucial to different stakeholders due to differences in focus. Therefore, it is difficult to pinpoint the most important key forces to consider. The government, for example will see the outcomes from the implementation of policies and laws as the most important elements in the macro-environment because they will want good improvements in sustainability as a return on their effort. Associations can work together as a group to establish a standard set of policies and guidelines that can be adjusted to suit every sector (Dickson \& Arcodia, 2010) whereas local governments may see guidelines from the central government as the most important factors because they will only undertake the responsibility for sustainable development with the assistance of the central government. Organizations may see financing as the most critical threat because they will want a return on their investments. However, the public may want social and environmental considerations viewed as top priority due to the impact they may cause on their daily lives. Technological threats can be mitigated by using knowledge acquired from the coordination of national and domestic industries and from research and development and assistance systems created by the government.

From this literature research, it can be see that the best way for an organization to mitigate threats is by considering each level separately and consider all opportunities present at that level. Once all threats at that particular stage have been mitigate to enough of an extent at that point, then the organization should move onto the next stage. The results from this analysis can help related government agencies, private sectors; non-governmental organizations and community have better comprehend the specific nature of the associations among these key forces and their role, while further expanding the understanding of sustainable development.

Sustainability is a concept that is gaining complexity as it sits in the different level of stakeholders and there is a necessity to develop a comprehensive framework to assist organizations in identifying better ways to manage 
and communicate sustainability practices (Pérez \& Bosque, 2014). In conclusion, the importance of knowing the macro-environment in a country is crucial because these key forces represent the opportunities and threats in achieving sustainability in an organization.

\section{Acknowledgments}

The author wishes to express her gratitude to her Supervisor, Dr. Yi-Shin, Deng who was abundantly helpful and offered invaluable assistance, support and guidance.

\section{References}

Adelle, C., Hertin, J., \& Jordan, A. (2006). Sustainable Development 'Outside' the European Union: What Role for Impact Assessment? European Environment, 16, 57-62.

Byars, L. (1991). Strategic Management: Formulation and Implementation: Concepts and Cases. New York, NY: Harper Collins.

Chao, C. W., Ma, H. W., \& Heijungs, R. (2013). The Green Economy Mirage? Examining the Environmental Implications of Low Carbon Growth Plans in Taiwan. Journal of Industrial Ecology, 17(6), 835-845.

Chen, F. L. (2008). Beyond Welfare Productivism: A Case Study of Social Protection for Population Ageing in Taiwan. Paper presented at the International Conference of Asian Social Protection in Comparative Perspective, National University of Singapore, Singapore.

Council for Economic Planning and Development, E. Y. (2004). Taiwan Agenda 21: Vision and Strategies for National Sustainable Development.

Davis, P., Huang, H. Y., \& Liu, W. C. (2010). Heritage, local communities and the safeguarding of 'Spirit of Place' in Taiwan. Museum and Society, 8(2), 80-89.

Department of Information Services, E. Y. (2014). 11 Organizations Receive Sustainable Development Award [Press release]

Dickson, C., \& Arcodia, C. (2010). Promoting sustainable event practice: The role of professional associations. International Journal of Hospitality Management, 29(2), 236-244.

Friedman, E. (2006). China's Rise, Taiwan's Dilemmas and International Peace London. New York: Routledge.

Heikkila, T., \& Isett, K. R. (2007). Citizen Involvement and Performance Management in Special-Purpose Governments. Public Administration Review, 67, 238-248.

Hsiao, H. C. (2008). 'Ecology' and Indigenous Political and Cultural Struggles in Taiwan: a Case Study of Two Atayal Villages. Paper presented at the The Fifth EATS Conference, Prague.

Hsu, S. (2013). Lessons in Sustainable Development from China \& Taiwan. Comparative Studies of Sustainable Development in Asia (pp. 112). New York: Palgrave Macmillan. http://dx.doi.org/10.1057/9781137358509

Hung, L.-J., Tsai, S.-S., Chen, P.-S., Yang, Y.-H., Liou, S.-H., Wu, T.-N., \& Yang, C.-Y. (2012). Traffic Air Pollution and Risk of Death from Breast Cancer in Taiwan: Fine Particulate Matter (PM2.5) as a Proxy Marker. Aerosol and Air Quality Research, 12, 275-282.

Keating, M. (1992). The Earth Summit's Agenda for Change. Earth Summit Times.

Kim, M.-C., \& Kim, Y.-H. (2014). Corporate social responsibility and shareholder value of restaurant firms. International Journal of Hospitality Management, 40, 120-129.

Ministry of Foreign Affairs, R. O. C., Taiwan. (2010). Social Welfare. Retrieved March 13, 2015, from http://www.taiwan.gov.tw/ct.asp?xItem=27604\&ctNode $=1926 \& \mathrm{mp}=1001$

MOEA. (2003). Taiwan Energy Statistics Annual Report. Ministry of Economic Affairs, Taipei (Taiwan).

MOEA. (2008). Framework of Taiwan's Sustainable Energy Policy. Bureau of Energy, Ministry of Economic Affairs, Taiwan R.O.C.

NCSD. (2004). 2003 Annual Report on National Sustainable Development (pp. 1-52): National Council for Sustainable Development, Taiwan, R.O.C.

NCSD. (2005). 2004 Annual Report on National Sustainable Development (pp. 1-103): National Council for Sustainable Development, Taiwan, R.O.C.

NCSD. (2006). 2005 Annual Report on National Sustainable Development (pp. 1-101): National Council for Sustainable Development, Taiwan, R.O.C. 
NCSD. (2007). 2006 Annual Report on National Sustainable Development (pp. 1-57): National Council for Sustainable Development, Taiwan, R.O.C.

NCSD. (2008). 2007 Annual Report on National Sustainable Development (pp. 1-54): National Council for Sustainable Development, Taiwan, R.O.C.

NCSD. (2009). 2008 Annual Report on National Sustainable Development (pp. 1-50): National Council for Sustainable Development, Taiwan, R.O.C.

NCSD. (2010). 2009 Annual Report on National Sustainable Development (pp. 52-201): National Council for Sustainable Development, Taiwan, R.O.C.

NCSD. (2011). 2010 Annual Report on National Sustainable Development (pp. 1-50): National Council for Sustainable Development, Taiwan, R.O.C.

NCSD. (2012). 2011 Annual Report on National Sustainable Development (pp. 1-51): National Council for Sustainable Development, Taiwan, R.O.C.

NCSD. (2013). 2012 Annual Report on National Sustainable Development (pp. 1-85): National Council for Sustainable Development, Taiwan, R.O.C.

NCSD. (2014). 2013 Annual Report on National Sustainable Development (pp. 1-58): National Council for Sustainable Development, Taiwan, R.O.C.

OECD. (2006). Good Practices in the National Sustainable Development Strategies of OECD Countries: Organisation for Economic Co-operation and Development.

Olsen, M. D. (2004). Literature in strategic management in the hospitality industry. International Journal of Hospitality Management, 23(5), 411-424. http://dx.doi.org/10.1016/j.ijhm.2004.10.003

Olsen, M. D., \& Roper, A. (1998). Research in strategic management in the hospitality industry. International Journal of Hospitality Management, 17, 111-124.

Pérez, A., \& Bosque, I. R. D. (2014). Sustainable Development and Stakeholder Relations Management: Exploring Sustainability Reporting in the Hospitality Industry from a SD-SRM Approach. International Journal of Hospitality Management, 42, 174-187.

Phillips, J. J. (1996). Accountability in Human Resource management. Houston: Gulf.

Porter, M. (1985). Competitive Advantage. New York: Free Press.

Shao, K. T., Peng, C. I., Yen, E., Lai, K. C., Wang, M. C., Lin, J., ... Chen, S. Y. (2007). Integration of Biodiversity Databases in Taiwan and Linkage to Global Databases. Data Science Journal, 6(Supplement), S2-S10.

Shih, Y. L., Chen, N. T., Tzeng, C. T., Hsieh, M. C., \& Liu, K. S. (2013). A Study on Education of Sustainable Development in Taiwan-using Energy Resource Centres in Public Middle and Elementary Schools as an Example. Paper presented at the Sustainable Building Conference 2013, Coventry University.

Su, W. J., Chan, T. C., Chuang, P. H., Liu, Y. L., Lee, P. I., Liu, M. T., \& Chuang, J. H. (2015). Estimating Influenza Vaccine Effectiveness using Routine Surveillance Data among Children Aged 6-59 Months for Five Consecutive Influenza Seasons. International Journal of Infectious Diseases, 30(0), 115-121. http://dx.doi.org/10.1016/j.jij.2014.11.011

Tsai, W.-T. (2010). Energy sustainability from analysis of sustainable development indicators: A case study in Taiwan. Renewable and Sustainable Energy Reviews, 14(7), 2131-2138. http://dx.doi.org/10.1016/j.rser.2010.03.027

Tsay, Y. Y. (2009). The Impacts of Economic Crisis on Green Consumption in Taiwan. Paper presented at the Portland International Center for Management of Engineering and Technology, Portland, Oregon USA.

Wei, C. H., \& Chung, M. C. (2003). Grey Statistics Method of Technology Selection for Advanced Public Transportation Systems: The Experience of Taiwan. IATSS Research, 27(2), 66-72. http://dx.doi.org/10.1016/S0386-1112(14)60145-X

Wu, I. C., \& Chang, S. (2013). Visual Req Calculation Tool for Green Building Evaluation in Taiwan. Automation in Construction, 35, 608-617. http://dx.doi.org/10.1016/j.autcon.2013.01.006

Yophy, H., Jeffrey, B. Y., \& Yu, P. C. (2011). The Long-term Forecast of Taiwan's Energy Supply and Demand: LEAP Model Application. Energy Policy, 39(11), 6790-6803. http://dx.doi.org/10.1016/j.enpol.2010.10.023 


\section{Copyrights}

Copyright for this article is retained by the author(s), with first publication rights granted to the journal.

This is an open-access article distributed under the terms and conditions of the Creative Commons Attribution license (http://creativecommons.org/licenses/by/3.0/). 